\title{
Photophysical Parameters, Excitation Energy Transfer, and Photoreactivity of 1,4-Bis(5-phenyl-2-oxazolyl)benzene (POPOP) Laser Dye
}

\author{
Samy A. El-Daly, ${ }^{1,2}$ Saleh A. El-Azim, ${ }^{1}$ Farouk M. Elmekawey, ${ }^{3}$ Bahgat Y. Elbaradei, ${ }^{3}$ \\ Sayed A. Shama, ${ }^{4}$ and Abdullah M. Asiri ${ }^{2,5}$ \\ ${ }^{1}$ Department of Chemistry, Faculty of Science, Tanta University, Tanta 31527, Egypt \\ ${ }^{2}$ Chemistry Department, Faculty of Science, King Abdulaziz University, P.O. Box 80203, Jeddah 21589, Saudi Arabia \\ ${ }^{3}$ Department of Physics, Faculty of Science, Tanta University, Tanta 31527, Egypt \\ ${ }^{4}$ Faculty of Engineering, MUST, 6th of October City, Egypt \\ ${ }^{5}$ Center of Excellence for Advanced Materials Research, King Abdul Aziz University, P.O. Box 80203, Jeddah 21589, Saudi Arabia \\ Correspondence should be addressed to Samy A. El-Daly, samyeldaly@yahoo.com
}

Received 20 February 2012; Accepted 6 April 2012

Academic Editor: Vincenzo Augugliaro

Copyright ( $) 2012$ Samy A. El-Daly et al. This is an open access article distributed under the Creative Commons Attribution License, which permits unrestricted use, distribution, and reproduction in any medium, provided the original work is properly cited.

\begin{abstract}
The effect of solvents on the absorption and emission spectra of 1,4-bis(5-phenyl-2-oxazolyl)benzene (POPOP) laser dye has been studied in various solvents at $298 \mathrm{~K}$. A bathochromic shift was observed in absorption and fluorescence spectra upon increase of solvent polarity, which indicates that this transition is $\pi-\pi^{*}$. The ground and excited state dipole moments were calculated as 2.23 and 6.34 Debye, respectively. The dye solution in $\mathrm{MeOH}, n$-heptane, and methyl isobutyl ketone gives laser emission in the blue region upon excitation by a $337.1 \mathrm{~nm}$ nitrogen pulse; the gain coefficient and emission cross section as well as normalized photostability have been determined. Excitation energy transfer from POPOP to rhodamine B and fluorescine was studied to improve the laser emission from these dyes. Such an energy transfer dye laser system (ETDL) obeys a long range columbic energy transfer mechanism with a critical transfer distance, $R_{0}$, of 25 and $33 \AA$ and $k_{q}$ equal to $10.4 \times 10^{12}$ and $26.2 \times 10^{12} \mathrm{M}^{-1} \mathrm{~s}^{-1}$ for the POPOP/RB and POPOP/fluorescine pair, respectively. The POPOP dye is highly photostable in polar protic and polar aprotic solvents, while it displays photodecomposition in chloromethane solvent via formation of a contact ion pair. The photochemical quantum yield and rate of photodecomposition depend on the electron affinity of solvent.
\end{abstract}

\section{Introduction}

Fluorescent organic compounds possessing high Stokes shift values $[1,2]$ are prospective candidates for practical application in various fields of science and technology, where high concentrations or long optical paths are required [3, $4]$, for example, in scintillation techniques $[5,6]$, sunlight collection, and conversion of solar energy into electricity $[7,8]$, electroluminescent light sources (OLEDs) [9-11], and various biological applications, and so forth. Several physicochemical mechanisms can be applied to increase the fluorescence Stokes shift of organic compounds [12]; however, not all lead to emissions with high quantum yields [13].
The most popular and most studied is the excited state proton transfer reaction $[14,15]$; however, it is usually connected with high radiationless excitation energy losses [16]. To our understanding, excited state conformational transformations resulting in the formation of more planar molecular structures [17-19] have several advantages in producing high Stokes shifted fluorescence emissions [20] over the alternative twisting mechanisms [21], which also induce radiationless excited state deactivation in most of the known cases [22].

Derivatives of 1,2-bis-(5-phenyloxazol-2-yl)benzene [23$25]$ are ortho analogs of the well-known scintillation luminophore POPOP [1,4-bis-(5-phenyloxazol-2-yl)benzene]. 


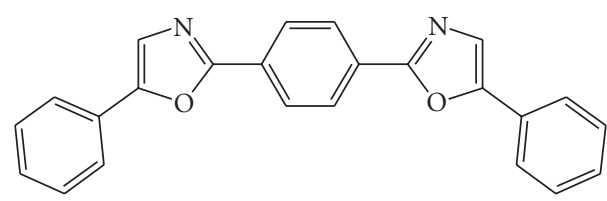

1,4-Bis(5-phenyl-2-oxazolyl)benzene (POPOP)

SCHEMe 1

They belong to the class of efficient fluorescent organic compounds with abnormally high Stokes shifts [26]. In contrast to their planar paraisomers [27], molecules of the title series are characterized by essential nonplanarity caused by the steric repulsion of two bulky heterocyclic moieties introduced into the orthopositions of the central benzene ring [28]. The resulting disruption of intramolecular conjugation shifts the electronic absorption spectra of ortho-POPOPs towards the shorter-wavelength region with respect to the absorption of their planar paraisomers.

Further increase of the Stokes shift values is possible by combination of several photophysical mechanisms in one molecule: for example, excited state planarization and solvatochromic effects. Asymmetrization of the electronic density distribution by introduction of highly electron-donating and/or electron-withdrawing substituents into the orthoPOPOP molecule leads to a significant rise in its excited state dipole moment, increased sensitivity to solvent polarity, and thus enlarges the fluorescence Stokes shift in polar media [29]. In the present we report photophysical parameters, excitation energy transfer, and photoreactivity of POPOP laser dye (Scheme 1).

\section{Experimental}

1,4-Bis (5-phenyl-2-oxazolyl)benzene (POPOP), fluorescine, and rhodamine B (Aldrich) were used without further purification. All solvents used in this work were of spectroscopic grade and were preliminary checked for the absence of absorbing or fluorescent impurities within the scanned spectral ranges. UV-Visible electronic absorption spectra were recorded on a Shimadzu UV-Vis 1650-PC spectrophotometer and steady state fluorescence spectra were measured using a rectangular quartz cell of $0.2 \mathrm{~cm}$ path length to minimize the reabsorption of emitted photons; the emission was monitored at $90^{\circ}$. The fluorescence quantum yield $\left(\phi_{f}\right)$ was measured using the optically diluted solution to avoid reabsorption effects (absorption at excitation wavelength $\leq 0.1$ ) relative method with solution of 9,10-diphenylanthracene as reference standard [30-32]. Using the same excitation wavelength, the unknown quantum yield is calculated using the following [33-35]:

$$
\phi_{u}=\phi_{s} \times \frac{I_{u}}{I_{s}} \times \frac{A_{s}}{A_{u}} \times \frac{n_{u}^{2}}{n_{s}^{2}},
$$

where $\phi_{u}, \phi_{s}$ are the fluorescence quantum yield of the unknown and standard, respectively, $I$ is the integrated emission intensity, $A$ is the absorbance at excitation wavelength, and $n$ is the refractive index of the solvent. The oscillator strength $(f)$ of electronic transition and the transition dipole moment $\left(\mu_{12}\right)$ from ground to excited state was calculated in different solvents using (2) and (3) [36]:

$$
\begin{aligned}
f= & 4.32 \times 10^{-9} \int \varepsilon(\tilde{\nu}) d \widetilde{v} \\
& \text { or } f=4.32 \times 10^{-9} \Delta \widetilde{\nu}_{1 / 2} \varepsilon_{\max }, \\
\mu_{12}^{2}= & \frac{f}{4.72 \times 10^{-7} E_{\max }},
\end{aligned}
$$

where $\varepsilon(\widetilde{\nu})$ is the numerical value for the molar extinction coefficient measured in $\mathrm{dm}^{3} \mathrm{~mol}^{-1} \mathrm{~cm}^{-1}$ and $\tilde{\nu}$ is the wavenumber value in $\mathrm{cm}^{-1}$ and $E_{\max }$ is the energy maximum of absorption band in $\mathrm{cm}^{-1}$. The radiative decay rate constant $\left(k_{r}\right)$ of a fluorophore (or fluorescence rate constant) presents a fundamental photophysical property, which determines, together with the rates for radiation less processes, the fluorescence life time; the rate of fluorescence resonance energy transfer (FRET) is also directly proportional to the radiative decay rates of the donor. The inverse of the fluorescence rate constant is the radiative (natural) life time $\left(\tau_{0}\right)$ of the excited state and corresponds to the lifetime expected in the absence of radiation less decay processes. The dependence of the radiative decay rate on the environment is significant; namely, it increases with its polarizability. It can be theoretically predicted from the well-known StricklerBerg equation, which has its foundations in Einstein's spontaneous emission rate and Planck's black body radiation law [37]:

$$
k_{r}=\frac{1}{\tau_{0}}=2.88 \times 10^{-9} n^{2} \frac{\int F(\tilde{\nu}) d \nu}{\int F(\widetilde{\nu}) \tilde{\nu}^{-3} d \nu} \int \frac{\varepsilon(\tilde{\nu})}{\bar{\nu}} d \widetilde{\nu},
$$

where $F$ is the fluorescence intensity, $\tilde{\nu}$ is the wave number, and $\varepsilon(\widetilde{\nu})$ is the molar extinction coefficient at a particular wave number $\widetilde{\nu}$. For the ideal case of a negligible Stokes shift and a perfect mirror-image relationship of absorption and fluorescence spectrum, (4) simplifies to become the following [38]:

$$
k_{r}=\frac{1}{\tau_{0}}=2.88 \times 10^{-9} n^{2}\langle\widetilde{\nu}\rangle_{\mathrm{av}}^{2} \int \varepsilon(\widetilde{\nu}) d \widetilde{\nu},
$$

where $\langle\tilde{\nu}\rangle_{\text {av }}$ is the average wave number corresponding to the 0-0 transition. Thus, according to (2) we can write

$$
k_{r}=0.668\langle\nu\rangle_{\mathrm{av}}^{2} n^{2} f .
$$

The fluorescence life time can be calculated by using the equation:

$$
\tau=\tau_{0} \phi_{f} .
$$


TABLE 1: Absorption and fluorescence properties of POPOP in different solvents.

\begin{tabular}{|c|c|c|c|c|c|c|c|c|c|c|}
\hline Solvent & $\begin{array}{c}\lambda_{\mathrm{abs}} \\
(\mathrm{nm})\end{array}$ & $\begin{array}{c}\lambda_{f} \\
(\mathrm{~nm})\end{array}$ & $\begin{array}{c}\varepsilon \times \\
10^{4} \mathrm{~mol}^{-1} \mathrm{~cm}^{-1} \mathrm{dm}^{3}\end{array}$ & $f$ & $k_{r} \times 10^{8} \mathrm{~s}^{-1}$ & $\phi_{f}$ & $\begin{array}{c}\tau_{f} \\
(\mathrm{~ns})\end{array}$ & $k_{\mathrm{isc}} \times 10^{8}$ & $\sigma_{a} \times 10^{-16} \mathrm{~cm}^{2}$ & $\sigma_{e} \times 10^{-16} \mathrm{~cm}^{2}$ \\
\hline$n$-Heptane & 362 & 416 & 5.65 & 1.00 & 9.79 & 0.76 & 0.78 & 3.02 & 1.34 & 2.96 \\
\hline Carbon tetra chloride & 370 & 416 & 4.89 & 0.86 & 8.90 & 0.74 & 0.83 & 3.02 & 1.16 & 2.74 \\
\hline Benzene & 365 & 411 & 5.73 & 1.02 & 11.48 & 0.74 & 0.65 & 3.88 & 1.36 & 2.56 \\
\hline Toluene & 368 & 418 & 4.98 & 0.90 & 9.95 & 0.81 & 0.81 & 2.29 & 1.18 & 2.81 \\
\hline Diethyl ether & 362 & 411 & 5.12 & 0.93 & 8.67 & 0.73 & 0.84 & 3.15 & 1.22 & 2.88 \\
\hline $\begin{array}{l}\text { Methyl isobutyl } \\
\text { ketone }\end{array}$ & 365 & 418 & 4.81 & 0.80 & 7.93 & 0.68 & 0.86 & 3.63 & 1.14 & 2.46 \\
\hline Amyl alcohol & 365 & 424 & 4.33 & 0.79 & 7.95 & 0.85 & 1.07 & 1.36 & 1.03 & 2.58 \\
\hline Cyclohexane & 363 & 409 & 4.48 & 0.80 & 8.31 & 0.76 & 0.92 & 2.53 & 1.06 & 2.56 \\
\hline Acetone & 362 & 415 & 5.17 & 0.93 & 8.78 & 0.69 & 0.78 & 3.88 & 1.23 & 2.88 \\
\hline Ethanol & 363 & 424 & 4.92 & 0.97 & 9.15 & 0.75 & 0.82 & 2.98 & 1.17 & 3.03 \\
\hline Methanol & 361 & 424 & 4.83 & 0.89 & 8.09 & 0.75 & 0.93 & 2.58 & 1.15 & 2.82 \\
\hline Diethyl formamide & 368 & 425 & 5.00 & 0.95 & 9.62 & 0.77 & 0.80 & 2.83 & 1.19 & 2.89 \\
\hline Ethylene glycol & 367 & 439 & 3.25 & 0.57 & 5.82 & 0.92 & 1.58 & 0.47 & 0.77 & 2.1 \\
\hline Propylene carbonate & 365 & 430 & 4.87 & 0.94 & 9.58 & 0.82 & 0.85 & 2.10 & 1.16 & 3.12 \\
\hline
\end{tabular}

The intersystem crossing rate constant $\left(k_{\text {isc }}\right)$ is related to the quantum fluorescence yield $\phi_{f}$ for $\left(\phi_{f} \approx 1\right)$ by the approximate relationship:

$$
k_{\mathrm{isc}}=\frac{\left(1-\phi_{f}\right)}{\tau_{f}} .
$$

The photochemical quantum yield $\left(\phi_{c}\right)$ was calculated using the method that was previously described in detail [39] and light intensity was measured by using ferrioxalate actinometry [40].

\section{Results and Discussion}

3.1. Optical Absorption and Emission Spectra in Different Solvents. The steady state absorption and emission parameters of $1 \times 10^{-5} \mathrm{~mol} \mathrm{dm}^{-3}$ POPOP were recorded in various nonpolar, polar aprotic, and polar protic solvents and are summarized in Table 1. The absorption and emission spectrum of POPOP are shown in Figures 1 and 2, respectively. As shown in Figure 1, the solvent polarity shows a slight effect on the position of electronic absorption spectral maxima, indicating the polar character of POPOP in the ground state.

Fluorescence spectra, on the other hand, are more sensitive to solvent polarity. As solvent polarity increases, the emission spectra become red-shifted, Figure 2. This indicates that the singlet excited state of the POPOP molecule is more polar than the ground state. There is also a good mirror image relationship between absorption and fluorescence spectra. These facts, together with high molar absorptivities $\left(\varepsilon=32500-56500 \mathrm{~mol} \mathrm{dm}^{-3} \mathrm{~cm}^{-1}\right)$ and high oscillator strength $(f=0.57-1.02)$, are consistent with a strong $\pi-\pi^{*}$ transition with a small geometry change between electronic ground and excited states [41]. The fluorescence quantum yields $\phi_{f}$ are slightly affected by solvent properties; the values of $\phi_{f}$ in methyl isobutyl ketone $\left(\phi_{f}=0.68\right)$ and acetone

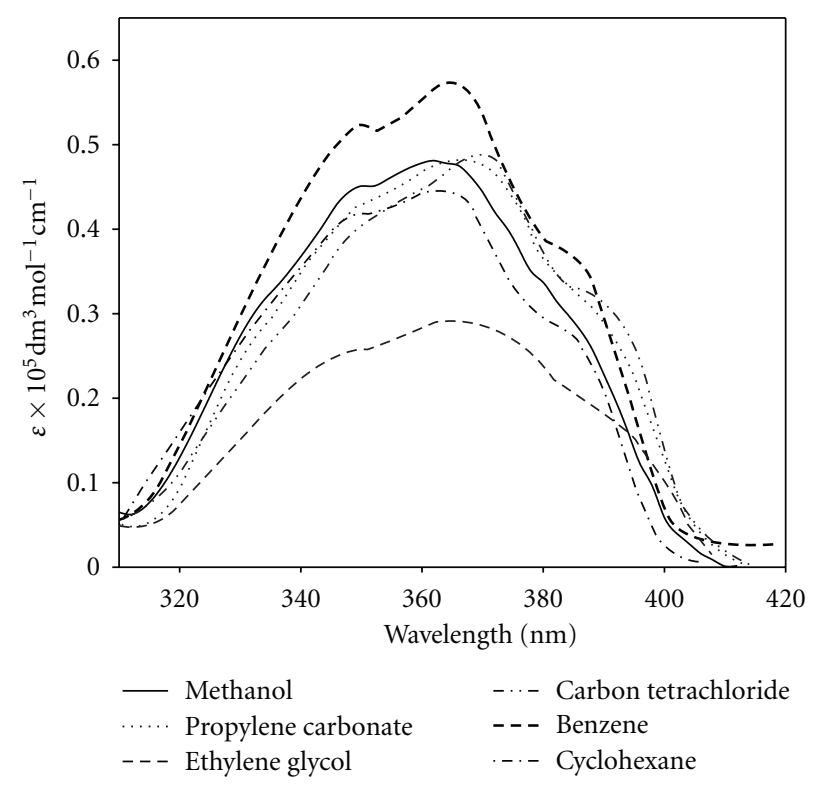

Figure 1: Absorption spectra of $1 \times 10^{-5} \mathrm{~mol} \mathrm{dm}^{-3}$ (POPOP) in different solvents.

$\left(\phi_{f}=0.69\right)$ are low due to the carbonyl group quenching the singlet excited state via enhancement of intersystem crossing $\left(S_{1} \rightarrow T_{1}\right)$, while the high value of fluorescence quantum yield in ethylene glycol $\left(\phi_{f}=0.92\right)$ can be explained in term of a cage effect and the role of medium viscosity which decrease the stretching and twisting molecular motion in the excited state, thereby decreasing the nonradiative process [42]. As seen in Table 1, the calculated fluorescence lifetimes obtained using the Strickler-Berg equation are very similar to the measured values. This is expected because the electronic absorption and fluorescence spectrum are nearly mirror image. 


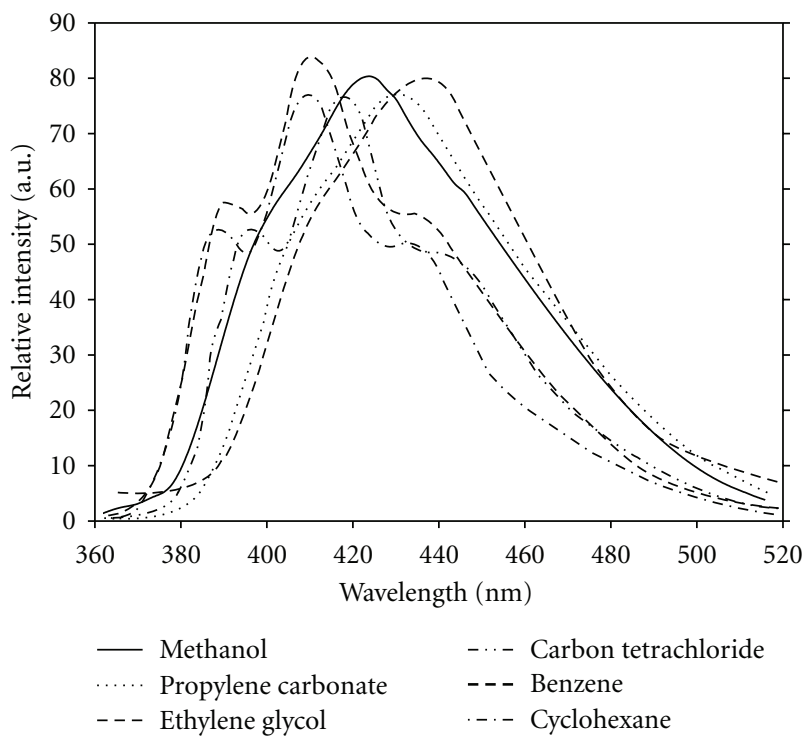

Figure 2: Emission spectra of $1 \times 10^{-5} \mathrm{~mol} \mathrm{dm}^{-3}$ (POPOP) in different solvents $\left(\lambda_{\mathrm{ex}}=380 \mathrm{~nm}\right)$.

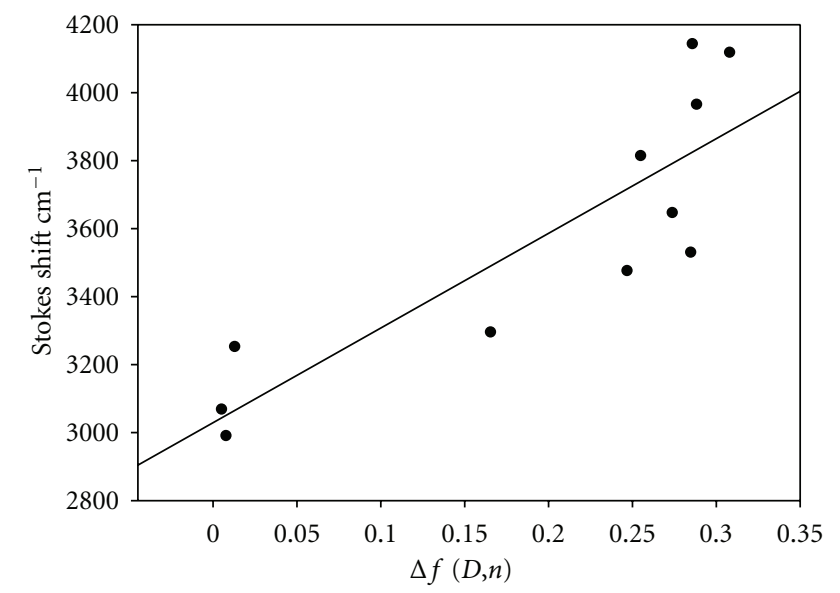

Figure 3: Stokes shift versus polarity $\Delta f$ of POPOP.

3.2. Determination of Dipole Moments. Analysis of the solvatochromic effect allows the estimation of difference in the dipole moment $(\Delta \mu)$ between the excited singlet and the ground state. This was achieved by applying the simplified Lippert-Mataga equation [43-45]

$$
\begin{gathered}
\Delta \tilde{\nu}_{\mathrm{st}}=\left(\tilde{\nu}_{\mathrm{abs}}-\tilde{\nu}_{\mathrm{em}}\right)=\frac{2\left(\mu_{e}-\mu_{g}\right)^{2}}{h c a^{3}} \Delta f+\text { Constant } \\
\Delta f=\frac{D-1}{2 D+1}-\frac{n^{2}-1}{2 n^{2}+1},
\end{gathered}
$$

where $h$ is the Planck's constant, $c$ is the velocity of light in vacuum, $\mu_{g}$ and $\mu_{e}$ are the dipole moments in the ground and excited states, and $a$ is the Onsager cavity radius of POPOP (taken to be between 4.2-4.7 $\AA$ [46]), $D, n$ are the dielectric and refractive index of the solvent, and $\Delta \widetilde{\nu}_{\text {st }}$ is the Stokes shift in $\mathrm{cm}^{-1}$, which increases with increase in solvent polarity, pointing to stabilization of excited state in polar solvents. Figure 3 shows a plot of Stokes shift versus the orientation polarizability $(\Delta f)$. The change in dipole moment upon excitation was calculated from the slope of the plot ( slope $=902 \mathrm{~cm}^{-1}$ ) and the cavity radius is $\Delta \mu=2.45$ Debye, indicating the polar nature of the excited singlet state.

Bakhshiev's and Kawski-Chamma-Viallet equations [4751] have been used for the treatment of observed spectral shifts to determine the ground and excited state dipole moments of POPOP.

Bakhshiev's formula is given in

$$
\tilde{\nu}_{\mathrm{abs}}-\tilde{\nu}_{\mathrm{em}}=S_{1} F_{1}(D, n)+\text { const. }
$$

where $\tilde{\nu}_{\text {abs }}$ and $\tilde{\nu}_{\text {em }}$ are the absorption and fluorescence maxima in wavenumber $\left(\mathrm{cm}^{-1}\right)$, respectively, $F_{1}$ (solvent polarity function) and $S_{1}$ are defined as follows:

$$
\begin{gathered}
F_{1}(D, n)=\frac{2 n^{2}+1}{n^{2}+2}\left[\frac{D-1}{D+2}-\frac{n^{2}-1}{n^{2}+2}\right], \\
S_{1}=\frac{2\left(\mu_{e}-\mu_{g}\right)^{2}}{h c a^{3}} .
\end{gathered}
$$

Kawski-Chamma-Vaillet's formula is given in

$$
\frac{\tilde{v}_{\mathrm{abs}}+\tilde{\nu}_{\mathrm{em}}}{2}=-S_{2} F_{2}(D, n)+\text { const. }
$$

$F_{2}$ and $S_{2}$ are defined as

$$
\begin{gathered}
F_{2}(D, n)=\frac{1}{2} F_{1}(D, n)+\frac{3}{2}\left(\frac{n^{4}-1}{\left(n^{2}+2\right)^{2}}\right), \\
S_{2}=\frac{2\left(\mu_{e}^{2}-\mu_{g}^{2}\right)}{h c a^{3}},
\end{gathered}
$$

where the symbols have their usual meaning as given in (9). The parameters $S_{1}$ and $S_{2}$ can be calculated from (12) and (15); they are the slope of straight lines Figure 4, and the values of $\mu_{g}$ and $\mu_{e}$ can be obtained from (8) and (10)

$$
\begin{aligned}
& \mu_{g}=\frac{\left(S_{2}-S_{1}\right)}{2}\left[\frac{h c a^{3}}{2 S_{1}}\right]^{1 / 2}, \\
& \mu_{e}=\frac{\left(S_{2}+S_{1}\right)}{2}\left[\frac{h c a^{3}}{2 S_{1}}\right]^{1 / 2}, \\
& \mu_{e}=\frac{S_{1}+S_{2}}{S_{2}-S_{1}} \mu_{g} \quad\left(S_{2}>S_{1}\right) .
\end{aligned}
$$

The values of $S_{1}$ and $S_{2}$ were found to be 553 and $1152 \mathrm{~cm}^{-1}$, respectively. Thus the calculated values of $\mu_{g}$ and $\mu_{e}$ were found to be 2.23 and 6.34 , respectively.

3.3. Lasing Action and Fluorescence Quenching of POPOP. POPOP is characterized by a high fluorescence quantum yield, high molar absorptivity, large Stokes shift, and high photostability in most organic solvents. A solution $2 \times$ $10^{-3} \mathrm{~mol} \mathrm{dm}^{-3}$ of POPOP in methanol, $n$-heptane, and methl isobutyl ketone(MIK) gives laser emission when using 

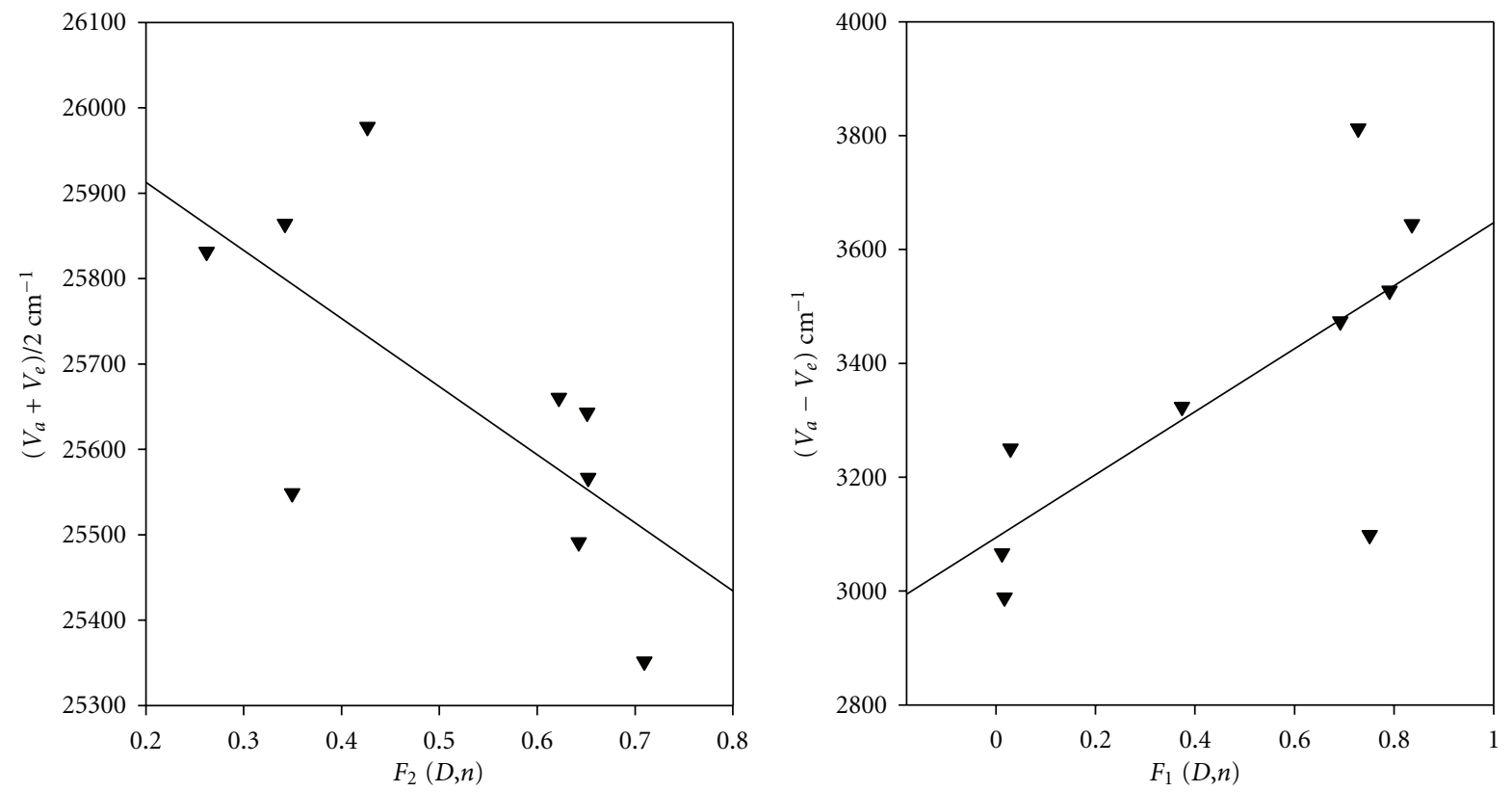

FIGURe 4: Stokes shift versus the functions $F_{1}(D, n)$ and $F_{2}(D, n)$ for POPOP in different solvents.

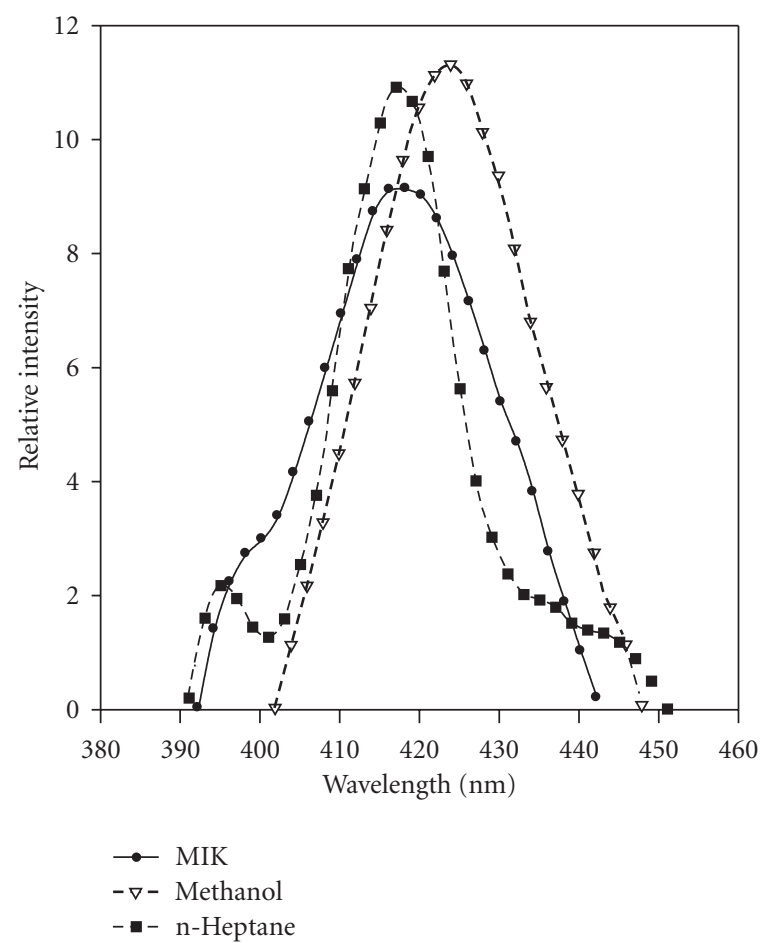

(a)

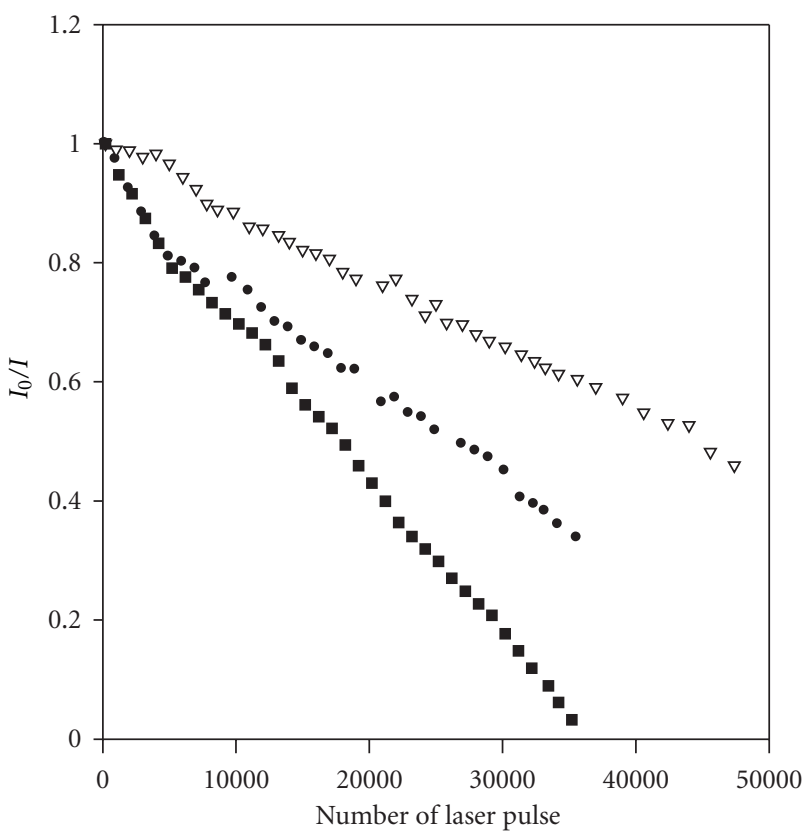

(b)

Figure 5: (a) Lasing range, (b) number of laser pulse versus $\left(I_{0} / I\right)$ of POPOP in different solvents using nitrogen pulsed laser $(\lambda=337 \mathrm{~nm})$.

a nitrogen pulsed laser $\left(\lambda_{\text {ex }}=337.1 \mathrm{~nm}\right)$ of 800 ps duration and $1.48 \mathrm{~mJ}$ pulse energy. The solution was taken in oscillator and amplifier cuvettes of $10 \mathrm{~mm}$ path length. The output energy of the laser dye was measured as a function of wavelength to determine the lasing range in different solvents Figure 5(a). The maximum gain coefficient $(\alpha)$ was calculated at the maximum laser emission by measuring the intensity $I_{L}$ of laser emission from the entire cell length $L$ and the intensity from the cell half length $I_{L / 2}$. One can calculate the laser gain emission from the following [52]:

$$
\alpha(\lambda)=\frac{2}{L} \ln \left[\frac{I_{L}}{I_{L / 2}}-1\right] .
$$


It is well known that gain occurs when the stimulated emission of photons exceeds the reabsorption or loss due to scattering. Therefore, gain is the increase in the number of emitted photons and is dependent on both wavelength and incident intensity. The cross section for the stimulated laser emission $\left(\sigma_{e}\right)$ of the dye was calculated at the laser emission maximum according to [53]

$$
\sigma_{e}=\frac{\lambda^{4} F(\lambda) \phi_{f}}{8 \pi c n^{2} \tau_{f}} .
$$

Here $\lambda$ is the emission wavelength, $n$ is the refractive index of the solvent, $c$ is the velocity of light, and $F(\lambda)$ is the normalized fluorescence line-shape function [54]. The normalized photostability is defined as the accumulated pump energy absorbed by the system per mole of dye molecules before the output energy falls to one half of its initial value using the following relation [55-57]:

$$
\begin{aligned}
& \text { Normalized photostability }(\mathrm{MJ} / \mathrm{mol}) \\
& =\frac{E_{\text {pulse }} N_{1 / 2}}{\pi \times r^{2} \times l \times C \times 10^{6}}
\end{aligned}
$$

where $E_{\text {pulse }}$ is the pulse energy in Joules, $N_{1 / 2}$ is the number of pulses to get the half of initial emission intensity Figure 5(b), $r$ is the radius of the laser beam on surface of sample in $\mathrm{cm}$ and $l$ is the sample thickness in $\mathrm{cm}(l=$ $1 \mathrm{~cm}$ ) and $c$ is the dye concentration $\mathrm{mol} \cdot \mathrm{dm}^{-3}$. The laser parameters and normalized photostability of POPOP are listed in Table 2.

The fluorescence quenching of POPOP has also been studied using rhodamine $\mathrm{B}$ (RB) and fluorescine as a quencher in methanol. Figure 6 shows the Stern-Volmer plot of POPOP using RB and fluorescine as a quencher by applying the Stern-Volmer relation in the form $[58,59]$ :

$$
\begin{aligned}
\frac{I_{0}}{I} & =1+k_{\mathrm{ET}} \tau_{f}[A] \\
& =1+k_{q}[A]
\end{aligned}
$$

where $k_{\mathrm{ET}}$ is the bimolecular quenching rate parameter, $\tau_{f}$ is the fluorescence lifetime of the donor in the absence of the acceptor taken as $0.93 \mathrm{~ns}$ in $\mathrm{MeOH}, I_{0}$ and $I$ are the fluorescence intensities in the absence and in the presence of quencher of concentration $[A]$ in $\mathrm{moldm}^{-3}$. A plot of $\left(\left(I_{0} / I\right)-1\right)$ versus acceptor concentration $[A]$ is given in Figure 6. From the slope of Figure $6, k_{\mathrm{Et}}$ has been calculated as $26.2 \times 10^{12} \mathrm{dm}^{3} \mathrm{~mol}^{-1} \mathrm{~s}^{-1}, 10.4 \times 10^{12} \mathrm{dm}^{3} \mathrm{~mol}^{-1} \mathrm{~s}^{-1}$ for the POPOP/RB and POPOP/fluorescine systems, respectively. These values are much higher than the diffusion controlled rate constant $\left(k_{\text {diff }}\right)$ in methanol. We determine the value of $k_{q}$ as $24.4 \times 10^{3} \mathrm{dm}^{3} \mathrm{~mol}^{-1}, 9.66 \times$ $10^{3} \mathrm{dm}^{3} \mathrm{~mol}^{-1}$ for the POPOP/RB and POPOP/fluorescine system, and we can calculate the quenching sphere by using the quenching sphere of action model $[60,61]$ :

$$
\ln \frac{I_{0}}{I}=V N_{A}[A]
$$

where $V$ the volume of the transient quenching sphere and $N_{A}$ the Avogadro's number, the radius of quenching sphere calculated to be $17.9 \AA$ for RB and $13.99 \AA$ for fluorescine.
TABle 2: Laser parameters of POPOP.

\begin{tabular}{lccccc}
\hline Solvent & $\begin{array}{c}\sigma_{e} \times \\
10^{-16} \mathrm{~cm}^{2}\end{array}$ & $\begin{array}{c}\text { Lasing } \\
\text { range }\end{array}$ & $\lambda_{\max }^{L} \mathrm{~nm}$ & $\alpha \mathrm{cm}^{-1}$ & $\begin{array}{c}\text { Normalized } \\
\text { photostability }\end{array}$ \\
\hline Methanol & 2.82 & $408-450$ & 424 & 1.25 & $20.94 \mathrm{MJ} / \mathrm{mol}$ \\
$n$-Heptane & 2.96 & $400-450$ & 417 & 0.89 & $8.41 \mathrm{MJ} / \mathrm{mol}$ \\
MIK & 2.46 & $395-440$ & 418 & 0.58 & $12.62 \mathrm{MJ} / \mathrm{mol}$ \\
\hline
\end{tabular}

From spectral data it is seen that there is a significant overlap between electronic absorption of acceptor (RB, fluorescine) and the emission spectrum of donor (POPOP) Figures 7(a) and 7(b). Applying Forester's resonance energy transfer mechanism, the critical transfer distance $R_{0}$ has been calculated for POPOP/RB and POPOP/fluorescine pair using the following relation [62]:

$$
\begin{gathered}
R_{0}^{6}=\frac{9000(\ln 10) k^{2} \phi_{f} J}{128 \pi^{5} n^{4} N_{A}}, \\
J=\frac{\int F_{D}(\lambda) \varepsilon_{A}(\lambda) \lambda^{4} d \lambda}{\int F_{D}(\lambda) d \lambda}, \\
R_{0}^{6}=1.25 \times 10^{-25} \frac{\phi_{f}}{n^{4}} J
\end{gathered}
$$

where $F_{D}(\lambda)$ is the corrected normalized fluorescence intensity of donor in the absence of the acceptor at wavelength $\lambda$, and $\varepsilon_{A}(\lambda)$ is the molar absorption coefficient of the acceptor at $\lambda, N_{A}$ Avogadro's number, the orientation factor $k^{2}=2 / 3$ was taken to be a reference state. Accordingly, the critical transfer distance $R_{0}$ was found as 25 and $33 \AA$ for $\mathrm{POPOP} / \mathrm{RB}$ and POPOP/fluorescine pair, respectively. This value is higher than that for collision energy transfer in which $R_{0}$ values are in the range of 4-6 [63]. The high value of the critical transfer distance as well as the quenching rate constant indicates that the underlying mechanism of energy transfer is that of resonance energy transfer due to longrange dipole-dipole interaction between excited donor and ground state acceptor.

3.4. Photoreactivity of POPOP in Chloromethane Solvents. The photoreactivity of POPOP was studied in $\mathrm{CCl}_{4}$, $\mathrm{CHCl}_{3}$ and $\mathrm{CH}_{2} \mathrm{CH}_{2}$ solvents. Upon irradiation of a $2 \times$ $10^{-5} \mathrm{~mol} \mathrm{dm}^{-3}$ solution of POPOP at $366 \mathrm{~nm}\left(I_{0}=4 \times\right.$ $10^{-6}$ Einstein $\min ^{-1}$ ), the absorbance of dye decreases upon increasing the irradiation time and a new absorption peak appears at $260 \mathrm{~nm}$ Figure 8. This indicates the formation of photoproduct in a solvent cage. The net photochemical quantum yields of the underlying reaction were calculated as $0.61,0.103$, and 0.067 for $\mathrm{CCl}_{4}, \mathrm{CHCl}_{3}$, and $\mathrm{CH}_{2} \mathrm{Cl}_{2}$, respectively (Figure 9). The formation of photoproduct is a one photon process as represented by the well-known mechanism [64-67]:

(1) $(\mathrm{POPOP})+h v$ $\longrightarrow{ }^{1}$ (POPOP $^{*}$ absorption of light

(2) ${ }^{1}(\mathrm{POPOP})^{*}$ $\longrightarrow \mathrm{POPOP}+h v$ fluorescence 

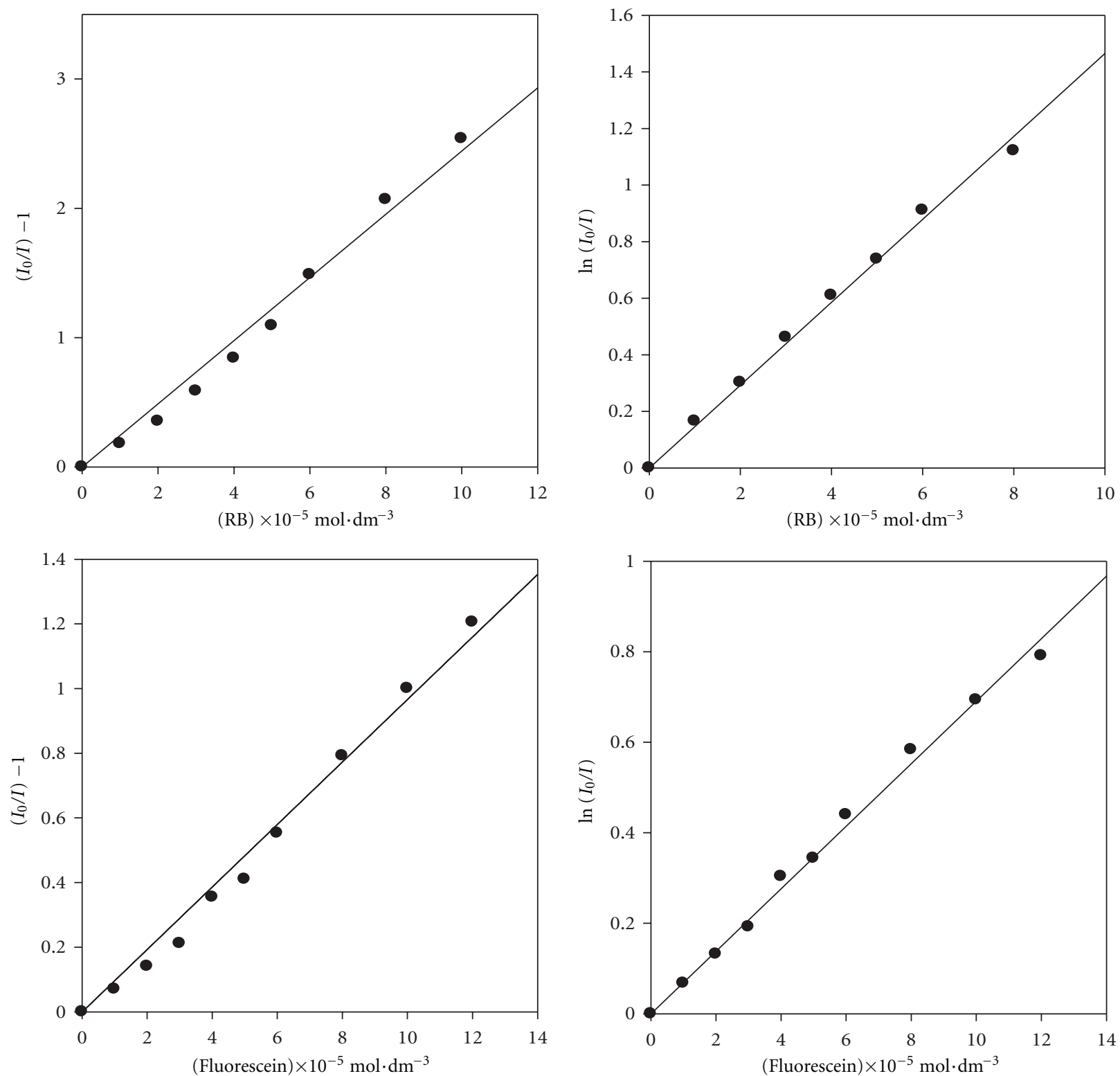

FigURE 6: Stern-Volmer plots for fluorescence quenching of $1 \times 10^{-5} \mathrm{~mol} \mathrm{dm}^{-3}$ POPOP by RB and fluorescine in methanol $\left(\lambda_{\mathrm{ex}}=337 \mathrm{~nm}\right)$.

(3) ${ }^{1}(\mathrm{POPOP})^{*}+\mathrm{CH}_{n} \mathrm{Cl}_{4-n}$ $\longrightarrow{ }^{1}\left[\mathrm{POPOP} \cdots \mathrm{CH}_{n} \mathrm{Cl}_{4-n}\right]^{*}$ exciplex

(4) ${ }^{1}\left[\mathrm{POPOP} \cdots \mathrm{CH}_{n} \mathrm{Cl}_{4-n}\right]^{*}$ $\longrightarrow\left[\mathrm{POPOP}^{\bullet+\delta} \ldots{ }^{\cdot-\delta} \mathrm{CH}_{n} \mathrm{Cl}_{3-n}\right]$ electron transfer

(5) $\left[\mathrm{POPOP}^{\bullet+\delta} \ldots{ }^{\cdot-\delta} \mathrm{CH}_{n} \mathrm{Cl}_{3-n}\right]$

$\longrightarrow \mathrm{POPOP}^{\bullet+\delta} \mathrm{Cl}^{-}+{ }^{\bullet} \mathrm{CH}_{n} \mathrm{Cl}_{3-n}$ contact ion pair

It was proposed that the electron transfer from the excited singlet POPOP to $\mathrm{CH}_{n} \mathrm{Cl}_{n-4}$ within the transient excited charge transfer complex (exciplex) is the main primary photochemical process. This leads to the POPOP radical cation, a chloride ion and a chloromethyl radical in the solvent cage Step (5).

The formation of constant ion pair usually occurs by electron transfer from excited donor molecule $(\mathrm{POPOP})^{*}$ to the acceptor $\left(\mathrm{CH}_{n} \mathrm{Cl}_{n-4}\right)$. The rate constant of photoreactivity of POPOP was calculated by applying the simple first order rate equation:

$$
\ln \frac{A_{0}-A_{\infty}}{A_{t}-A_{\infty}}=k t,
$$

where $A_{0}, A_{t}$, and $A_{\infty}$ are the initial absorbance, absorbance at time $(t)$, and infinity, respectively. The rate constant was found to be 0.024, 0.011, and $0.005 \mathrm{~min}^{-1}$ in $\mathrm{CCl}_{4}, \mathrm{CHCl}_{3}$, and $\mathrm{CH}_{2} \mathrm{Cl}_{2}$, respectively. It was found that the net photochemical quantum yield $\left(\phi_{c}\right)$ and the observed rate constant 


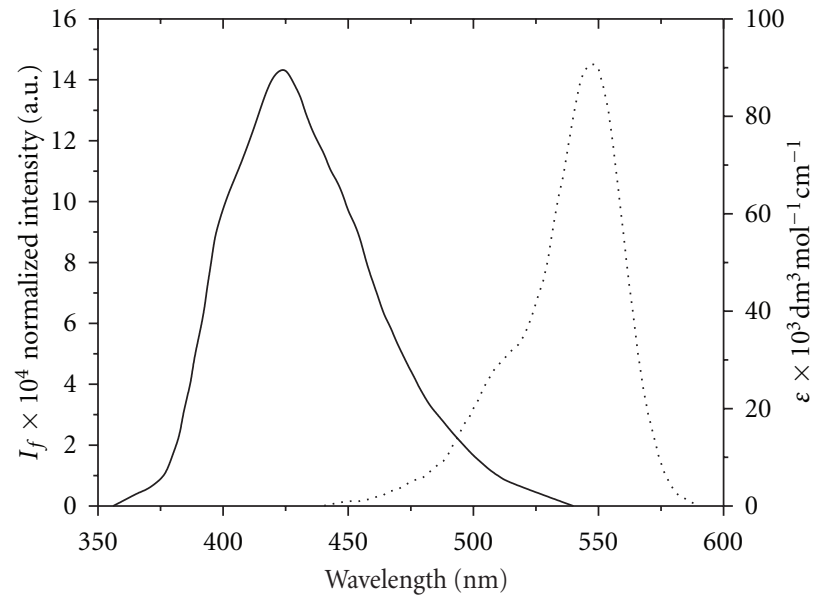

(a)

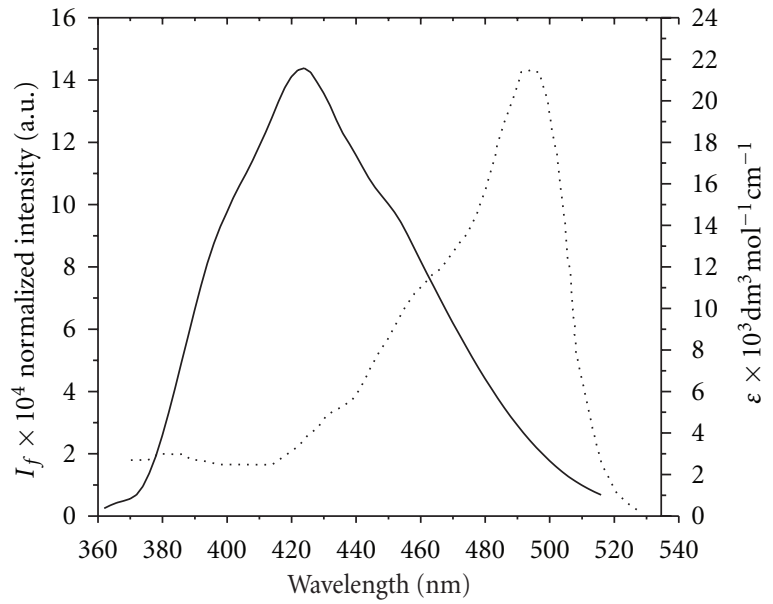

(b)

Figure 7: (a) Normalized emission spectrum of $1 \times 10^{-5} \mathrm{~mol} \mathrm{dm}^{-3}$ of POPOP $(-)$ and absorption spectrum $(\cdots)$ of $1 \times 10^{-5} \mathrm{~mol} \mathrm{dm}{ }^{-3}$ of $\mathrm{RB}$ in methanol, (b) normalized emission spectrum of $1 \times 10^{-5} \mathrm{~mol} \mathrm{dm}{ }^{-3}$ of POPOP $(-)$ and absorption spectrum $(\cdot \cdots)$ of $1 \times$ $10^{-5} \mathrm{~mol} \mathrm{dm}^{-3}$ of fluorescine in methanol.

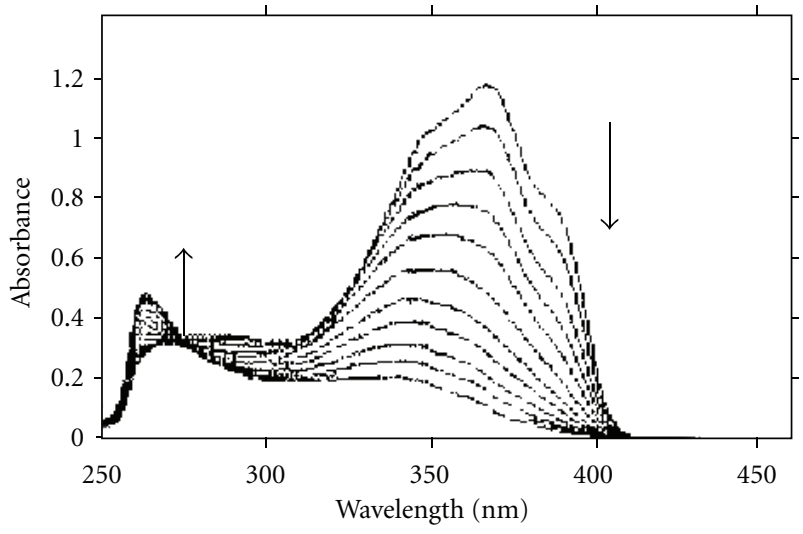

FIGURE 8: The change in absorption spectra of $2 \times 10^{-5} \mathrm{~mol} \mathrm{dm}^{-3}$ of POPOP in $\mathrm{CCl}_{4}$ as a result of UV irradiation $\left(\lambda_{\mathrm{ex}}=366 \mathrm{~nm}\right)$. The irradiation times at decreasing absorbance are $0.0,1,2,3,4,5,6,7$, 8,10 , and $11 \mathrm{~min}$.

(k) increases with increase in the electron affinity $\left(E_{A}\right)$ of chloromethane solvents ( $E_{A}$ equal 2.12, 1.75 and $1.36 \mathrm{eV}$ for $\mathrm{CCl}_{4}, \mathrm{CHCl}_{3}$ and $\mathrm{CH}_{2} \mathrm{Cl}_{2}$, resp.), indicating that the electron affinity of the solvent plays a role in the photoreactivity and controls the photochemical reaction. The POPOP dye is highly photostable in polar protic and aprotic solvents, since no change in absorbance of dye was observed upon prolonged irradiation by using either 336 or $254 \mathrm{~nm}$ light for about 24 hours.

\section{Conclusion}

The ground and excited state dipole moments of POPOP were determined as 2.3 and 6.34 Debye, respectively. The dye solution in methanol, $n$-heptane, and methyl-isobutyl ketone

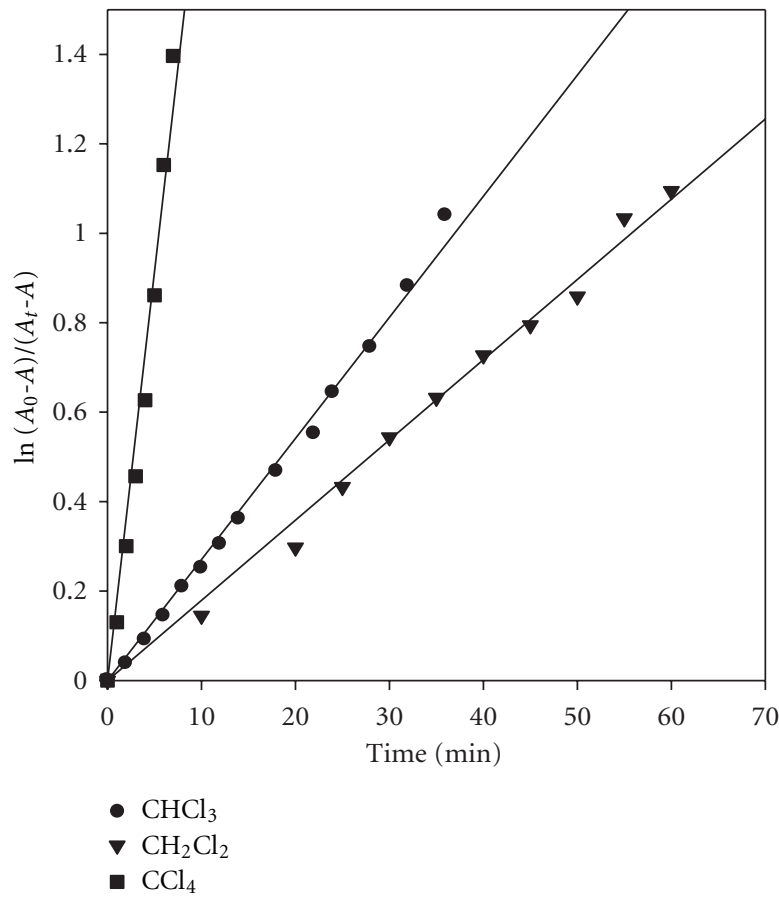

FIGURE 9: First order plots of photoreactivity of POPOP in chloromethane solvents.

gives laser emission in blue region with emission maximum in the range 417-450 $\mathrm{nm}$ upon pumping by nitrogen laser pulse. POPOP act as a good energy donor for rhodamine B and fluorescine laser dyes, the energy transfer rate constant and critical transfer distance are determined. POPOP dye is highly photostable in polar solvents but displays photodecomposition in chloromethane solvents via electron transfer from excited dye to solvent molecules. 


\section{References}

[1] J. R. Lakowicz, Principles of Fluorescence Spectroscopy, Springer Science, Singapore, 3d edition, 2006.

[2] B. Valeur, MolecularFluorescence, Wiley-VCH GmbH, Germany, 2002.

[3] M. Eichhorn, "Fluorescence reabsorption and its effects on the local effective excitation lifetime," Applied Physics B, vol. 96, no. 2-3, pp. 369-377, 2009.

[4] G. Bordeau, R. Lartia, and M. P. Teulade-Fichou, "Meta-Substituted triphenylamines as new dyes displaying exceptionally large Stokes shifts," Tetrahedron Letters, vol. 51, no. 33, pp. 4429-4432, 2010.

[5] J. B. Birks, The Theory and Practice of Scintillation Counting, Pergamon Press, Oxford, UK, 1967.

[6] C. Zorn, M. Bowen, S. Majewski et al., "Pilot study of new radiation-resistant plastic scintillators doped with 3hydroxyflavone," Nuclear Instruments and Methods in Physics Research. Section A, vol. 273, no. 1, pp. 108-116, 1988.

[7] N. S. Lewis and D. G. Nocera, "Powering the planet: chemical challenges in solar energy utilization," Proceedings of the National Academy of Sciences of the United States of America, vol. 103, no. 43, pp. 15729-15735, 2006.

[8] W. R. McNamara, R. C. Snoeberger, G. Li et al., "Acetylacetonate anchors for robust functionalization of $\mathrm{TiO} 2$ nanoparticles with Mn(II)-terpyridine complexes," Journal of the American Chemical Society, vol. 130, no. 43, pp. 14329-14338, 2008.

[9] C. W. Tang and S. A. Vanslyke, "Organic electroluminescent diodes," Applied Physics Letters, vol. 51, no. 12, pp. 913-915, 1987.

[10] N. Tamoto, C. Adachi, and K. Nagai, "Electroluminescence of 1,3,4-oxadiazole and triphenylamine-containing molecules as an emitter in organic multilayer light emitting diodes," Chemistry of Materials, vol. 9, no. 5, pp. 1077-1085, 1997.

[11] A. P. De Silva, D. B. Fox, A. J. M. Huxley, and T. S. Moody, "Combining luminescence, coordination and electron transfer for signalling purposes," Coordination Chemistry Reviews, vol. 205, no. 1, pp. 41-57, 2000.

[12] F. Vollmer, W. Rettig, and E. Birckner, "Photochemical mechanisms producing large fluorescence stokes shifts," Journal of Fluorescence, vol. 4, no. 1, pp. 65-69, 1994.

[13] V. V. Volchkov and B. M. Uzhinov, "Structural relaxation of excited molecules of heteroaromatic compounds," High Energy Chemistry, vol. 42, no. 3, pp. 153-169, 2008.

[14] S. M. Ormson and R. G. Brown, "Excited state intramolecular proton transfer part 1: ESIPT to nitrogen," Progress in Reaction Kinetics, vol. 19, pp. 45-91, 1994.

[15] D. Le Gourrierec, S. M. Ormson, and R. G. Brown, "Excited state intramolecular proton transfer part 2: Esipt to oxygen," Progress in Reaction Kinetics, vol. 19, no. 3, pp. 211-275, 1994.

[16] F. Vollmer and W. Rettig, "Fluorescence loss mechanism due to large-amplitude motions in derivatives of 2,2'-bipyridyl exhibiting excited-state intramolecular proton transfer and perspectives of luminescence solar concentrators," Journal of Photochemistry and Photobiology A, vol. 95, no. 2, pp. 143-155, 1996.

[17] R. Siebert, A. Winter, U. S. Schubert, B. Dietzek, and J. Popp, "Excited-state planarization as free barrierless motion in a $\pi$ Conjugated terpyridine," Journal of Physical Chemistry C, vol. 114, no. 14, pp. 6841-6848, 2010.
[18] C.-C. Yang, C.-J. Hsu, P.-T. Chou, H. C. Cheng, Y. O. Su, and M.-K. Leung, "Excited state luminescence of multi-(5-phenyl1, 3, 4-oxadiazo-2-yl) benzenes in an electron-donating matrix: exciplex or electroplex?" Journal of Physical Chemistry $B$, vol. 114, no. 2, pp. 756-768, 2010.

[19] R. Y. Iliashenko, N. Y. Gorobets, and A. O. Doroshenko, "New and efficient high Stokes shift fluorescent compounds: unsymmetrically substituted 1,2-bis-(5-phenyloxazol-2-yl)benzenes via microwave-assisted nucleophilic substitution of fluorine," Tetrahedron Letters, vol. 52, no. 39, pp. 5086-5089, 2011.

[20] A. O. Doroshenko, "Physicochemical principles of the creation of highly efficient organic luminophores with anomalously high stokes' shifts," Theoretical and Experimental Chemistry, vol. 38, no. 3, pp. 135-155, 2002.

[21] W. Rettig, "Charge separation in excited states of decoupled systems-TICT compounds and implications regarding the development of new laser dyes and the primary processes of vision and photosynthesis," Angewandte Chemie, vol. 25, pp. 971-988, 1986.

[22] Z. R. Grabowski, K. Rotkiewicz, and W. Rettig, "Structural changes accompanying intramolecular electron transfer: focus on twisted intramolecular charge-transfer states and structures," Chemical Reviews, vol. 103, no. 10, pp. 3899-4031, 2003.

[23] A. O. Doroshenko, L. D. Patsenker, V. N. Baumer et al., "Structure of sterically hindered aryl derivatives of five-membered nitrogen containing heterocyclic ortho-analogs of POPOP," Molecular Engineering, vol. 3, no. 4, pp. 353-363, 1994.

[24] A. O. Doroshenko, L. D. Patsenker, V. N. Baumer et al., "Structure of sterically hindered aryl derivatives of fivemembered nitrogen containing heterocyclic ortho-analogs of POPOP," Molecular Engineering, vol. 3, no. 4, pp. 353-363, 1994.

[25] A. O. Doroshenko, V. N. Baumer, A. A. Verezubova, and L. M. Ptyagina, "Molecular structure of unsubstituted oxadiazolic analog of ortho-POPOP and peculiarities of conformational structure of this class of sterically hindered organic compounds," Journal of Molecular Structure, vol. 609, no. 1-3, pp. 29-37, 2002.

[26] A. O. Doroshenko, A. V. Kirichenko, V. G. Mitina, and O. A. Ponomaryov, "Spectral properties and dynamics of the excited state structural relaxation of the ortho analogues of POPOPeffective abnormally large Stokes shift luminophores," Journal of Photochemistry and Photobiology A: Chemistry, vol. 94, no. 1, pp. 15-26, 1996.

[27] R. Ambats and E. Marsh, "The crystal structures of 2,2'p-phenylenehis(5-phenyloxazole)_'POPOP'” Acta Crystallographica, vol. 19, pp. 942-948, 1965.

[28] A. O. Doroshenko, V. N. Baumer, A. V. Kirichenko, V. M. Shershukov, and A. V. Tolmachev, "Molecular structural features of unsymmetrical ortho analogs of POPOP," Chemistry of Heterocyclic Compounds, vol. 33, no. 11, pp. 1341-1349, 1997.

[29] A. O. Doroshenko, "The effect of solvent on the spectral properties and Dynamics of structural relaxation of two excites-state ortho-analogs of popop with essentially different polarities," Chemical Physics Reports, vol. 18, no. 5, pp. 873879, 1999.

[30] W. H. Melhuish, "Quantum efficiencies of fluorescence of organic substan ces: effect of solvent and concentration of the fluorescent solute," Journal of Physical Chemistry, vol. 65, no. 2, pp. 229-235, 1961.

[31] J. B. Birks and D. J. Dyson, "The relations between the fluorescence and absorption properties of organic molecules," Proceedings of the Royal Society A, vol. 275, pp. 135-148, 1963. 
[32] W. R. Dawson and M. W. Windsor, "Fluorescence yields of aromatic compounds," The Journal of Physical Chemistry, vol. 72, pp. 3251-3260, 1968.

[33] G. A. Crosby and J. N. Demas, "Measurement of photoluminescence quantum yields. Review," The Journal of Physical Chemistry, vol. 75, no. 8, pp. 991-1024, 1971.

[34] J. C. Scaiano, Ed., Handbook of Organic Photochemistry, Harwood, Chichester, UK, 1991.

[35] A. Credi and L. Prodi, "From observed to corrected luminescence intensity of solution systems: an easy-to-apply correction method for standard spectrofluorimeters," Spectrochimica Acta. Part A, vol. 54, no. 1, pp. 159-170, 1998.

[36] B. J. Coe, J. A. Harris, I. Asselberghs et al., "Quadratic nonlinear optical properties of $N$-aryl stilbazolium dyes," Advanced Functional Materials, vol. 12, no. 2, pp. 110-116, 2002.

[37] B. Briks, Photophysics of Aromatic Molecules, Wiley, London, UK, 1970.

[38] G. A. Kumar and N. V. Unnikrishnan, "Energy transfer and optical gain studies of FDS: Rh B dye mixture investigated under cw laser excitation," Journal of Photochemistry and Photobiology A: Chemistry, vol. 144, no. 2-3, pp. 107-117, 2001.

[39] E.-Z. M. Ebeid, R. M. Issa, M. M. Ghoneim, and S. A. ElDaly, "Emission characteristics and micellization of cationic 1,4-bis( $\beta$-pyridyl-2-vinyl)benzene laser dye," Journal of the Chemical Society, Faraday Transactions 1: Physical Chemistry in Condensed Phases, vol. 82, no. 3, pp. 909-919, 1986.

[40] S. L. Murov, Handbook of Photochemistry, Marcel Dekker, New York, NY, USA, 1973.

[41] S. A. El-Daly, S. M. Al-Hazmy, E. M. Ebeid et al., "Spectral, acid-base, and laser characteristics of 1,4-Bis[ $\beta$-(2-quinolyl)vinyl]benzene (BQVB)," Journal of Physical Chemistry, vol. 100, no. 23, pp. 9732-9737, 1996.

[42] E.-Z. M. Ebeid, M. H. Abdel-Kader, R. M. Issa, and S. A. ElDaly, "Viscosity and medium effects on the fluorescence and photochemical behaviour of some aryl chalcones," Chemical Physics Letters, vol. 146, no. 3-4, pp. 331-336, 1988.

[43] E. Lippert, "Spektroskopische bestimmung des dipolmomentes aromatischer verbindungen im ersten angeregten Zustand," Zeitschrift für Elektrochemie, vol. 61, pp. 962-975, 1957.

[44] P. Suppan, "Invited review solvatochromic shifts: the influence of the medium on the energy of electronic states," Journal of Photochemistry and Photobiology, A: Chemistry, vol. 50, no. 3, pp. 293-330, 1990.

[45] S. A. El-Daly, M. Gaber, S. S. Al-Shihry, and Y. S. E. Sayed, "Photophysical properties, excitation energy transfer and laser activity of 3-(4'-dimethylaminophenyl)-1-(2-pyridinyl) prop2-en-1-one (DMAPP). A new potential laser dye," Journal of Photochemistry and Photobiology A, vol. 195, no. 1, pp. 89-98, 2008.

[46] G. H. Malimath, G. C. Chikkur, H. Pal, and T. Mukherjee, "Role of internal mechanisms in energy transfer processes in organic liquid scintillators," Applied Radiation and Isotopes, vol. 48, no. 3, pp. 359-364, 1997.

[47] L. Bilot and A. Kawski, "Zur theorie des einflusses von Lösungsmitteln auf die elektronenspektren der moleküle," Zeitschrift Naturforschung, vol. 17, p. 621, 1962.

[48] A. Kawski, "Uber die temperaturbhangigkeit der absorptions-und fluoreszenzspektren von 4-amino-phthalimid," Acta Physica Polonica, vol. 29, p. 507, 1966.

[49] A. Kawski, "On the estimation of excited-state dipole moments from solvatochromic shifts of absorption and fluorescence spectra," Zeitschrift für Naturforschung A, vol. 57, no. 5-6, pp. 255-262, 2002.
[50] R. Ghazy, S. A. Azim, M. Shaheen, and F. El-Mekawey, "Experimental studies on the determination of the dipole moments of some different laser dyes," Spectrochimica Acta. Part A, vol. 60, no. 1-2, pp. 187-191, 2004.

[51] L. Liu, Y. Sun, S. Wei, X. Hu, Y. Zhao, and J. Fan, "Solvent effect on the absorption and fluorescence of ergone: Determination of ground and excited state dipole moments," Spectrochimica Acta Part A, vol. 86, pp. 120-123, 2012.

[52] M. Rinke, H. Güsten, and H. J. Ache, "Photophysical properties and laser performance of photostable UV laser dyes. 1. Substituted p-quaterphenyls," Journal of Physical Chemistry, vol. 90, no. 12, pp. 2661-2665, 1986.

[53] L. G. Nair, "Dye lasers," Progress in Quantum Electronics, vol. 7, no. 3-4, pp. 153-268, 1982.

[54] G. Valverde-Aguilar, "Photostability of laser dyes incorporated in formamide $\mathrm{SiO}_{2}$ ORMOSILs," Optical Materials, vol. 28, no. 10, pp. 1209-1215, 2006.

[55] Y. Yang, M. Wang, G. Qian, Z. Wang, and X. Fan, "Laser properties and photostabilities of laser dyes doped in ORMOSILs," Optical Materials, vol. 24, no. 4, pp. 621-628, 2004.

[56] M. S. Mackey and W. N. Sisk, "Photostability of pyrromethene 567 laser dye solutions via photoluminescence measurements," Dyes and Pigments, vol. 51, no. 2-3, pp. 79-85, 2001.

[57] G. R. Penzer, An Introduction to Spectroscopy for Biochemistry, S. B. Brown, Editor, Academic Press, London, UK, 1980.

[58] N. J. Turro, Molecular Photochemistry, Benjamin, New York, NY, USA, 1967.

[59] A. Gilbert and J. Baggott, Essential of Molecular Photochemistry, Black-Well, London, UK, 1991.

[60] N. J. Turro, Modern Molecular Photochemistry, Benjamin, New York, NY, USA, 1968.

[61] I. M. Frank and S. J. Vavilov, "Über die wirkungssphare der auslöschunsvargänge in den flureszierenden flussing-keiten," Zeitschrift für Physiologie, vol. 69, p. 100, 1931.

[62] S. G. Schulman, "Acide-base chemistry of excited singlet state: fundamental and analytical implications," in Modern Fluorescence spectroscopy, E. L. Wehry, Ed., vol. 2, Plenum, New York, NY, USA, 1976.

[63] M. C. Biondic and R. Erra-Balsells, "Photochemical reaction of full-aromatic $\beta$-carbolines in halomethanes $2 . \mathrm{CHCl}_{3}$ : Electronic spectra and kinetics," Journal of Photochemistry and Photobiology, A: Chemistry, vol. 77, no. 2-3, pp. 149-159, 1994.

[64] M. C. Biondic and R. Erra-Balsells, "Photochemical reaction of $\beta$-carbolines in carbon tetrachloride-ethanol mixtures," Journal of Photochemistry and Photobiology, A: Chemistry, vol. 51, no. 3, pp. 341-353, 1990.

[65] M. C. S. Mastsuda, R. Kokado, and H. E. Inou, "The Photoconductivity in a $\mathrm{CCl}_{4}$ Solution of N,N-Dimethylaniline," Bulletin of the Chemical Society of Japan, vol. 43, p. 2994, 1970.

[66] R. E. Balsells and A. R. Farsca, "Photochemical reactions of aliphatic-amines in dichloromethane solution," Australian Journal of Chemistry, vol. 41, no. 1, pp. 103-110, 1988.

[67] L. Wolinski, Z. Turznski, and K. Witkowski, "Lichtstreubefunde zur kettenspaltung von polystyrol in sauerstoffreien $\mathrm{CCl}_{4}$ - und $\mathrm{CHCl}_{3}$-lösungen bei lichteinwirkung der wellenlängen $\lambda \geq 270$ nm," Die Makromolekulare Chemie, vol. 199, no. 12, pp. 2895-2907, 1987. 


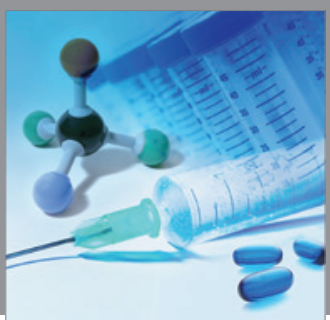

International Journal of

Medicinal Chemistry

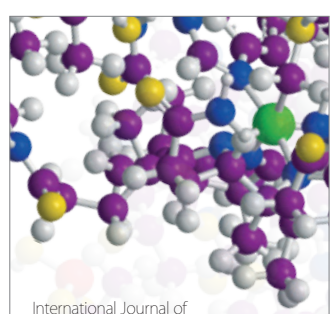

Carbohydrate Chemistry

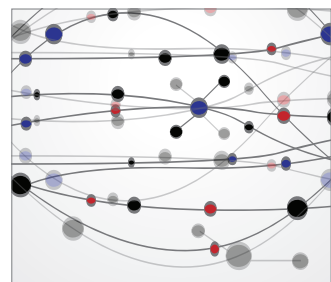

The Scientific World Journal
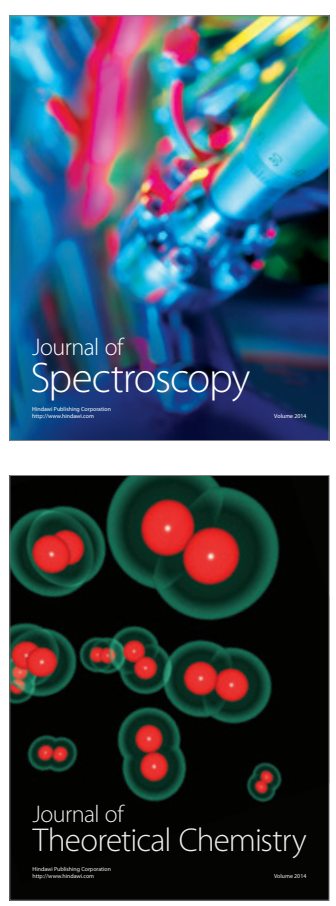
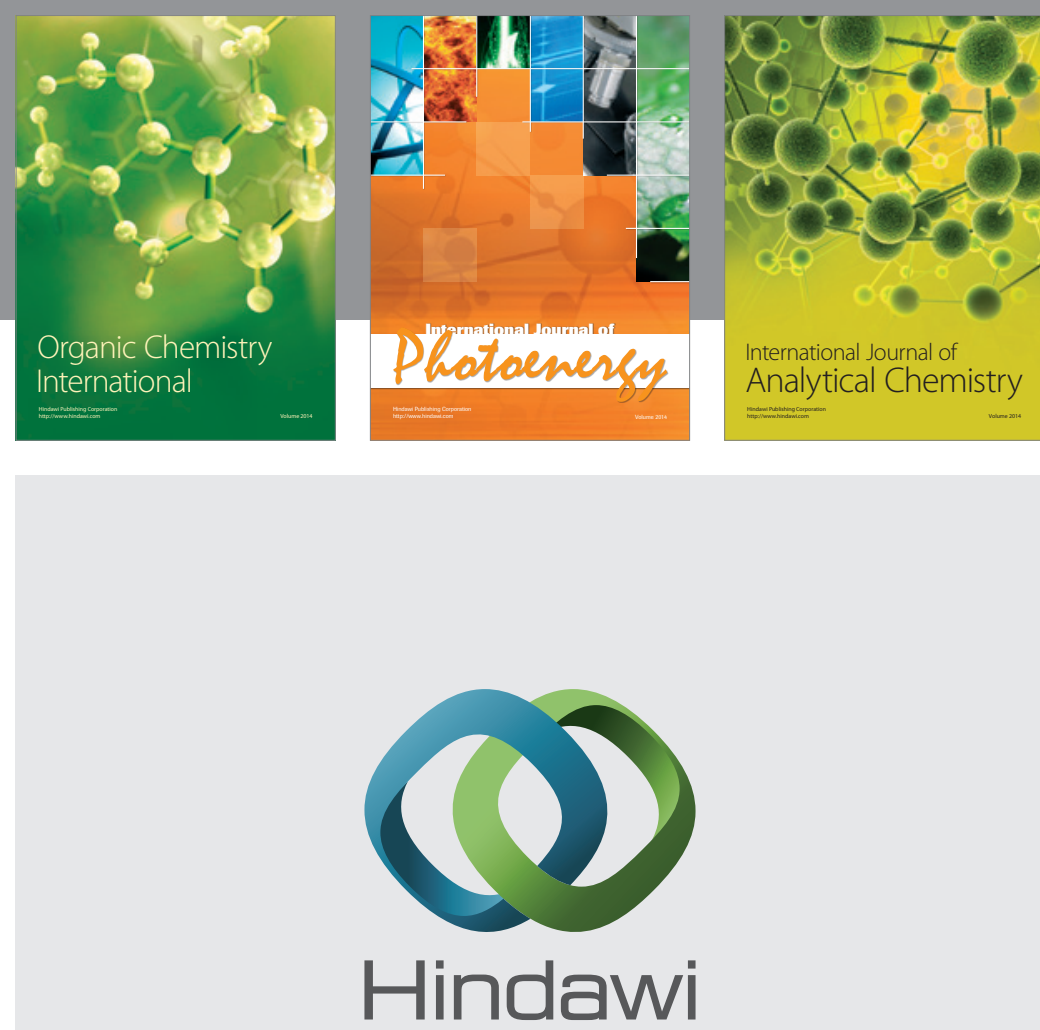

Submit your manuscripts at

http://www.hindawi.com
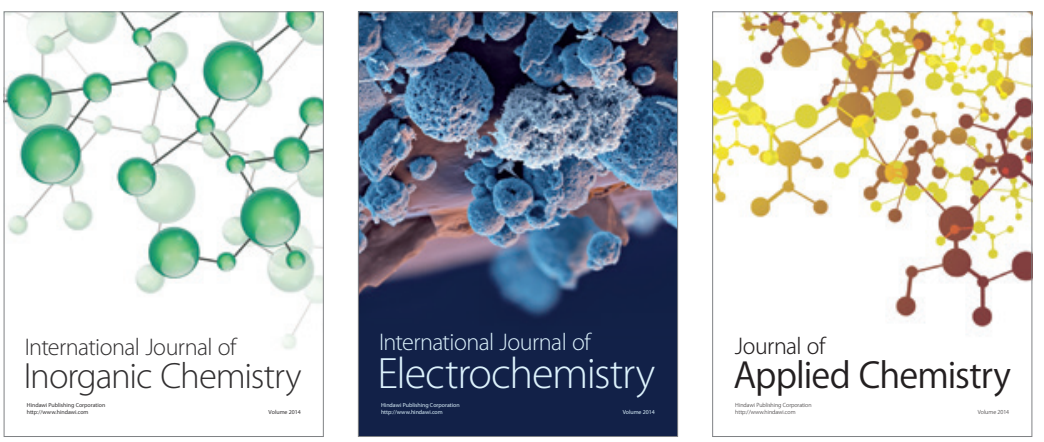

Journal of

Applied Chemistry
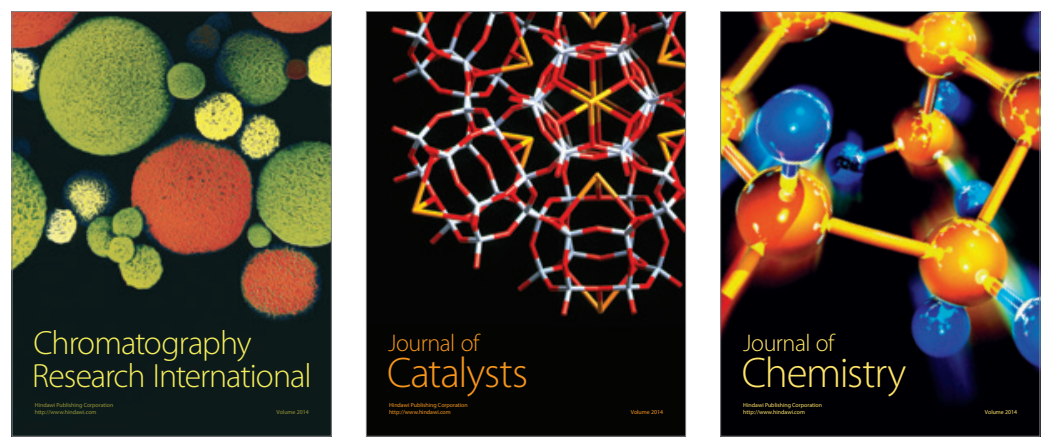
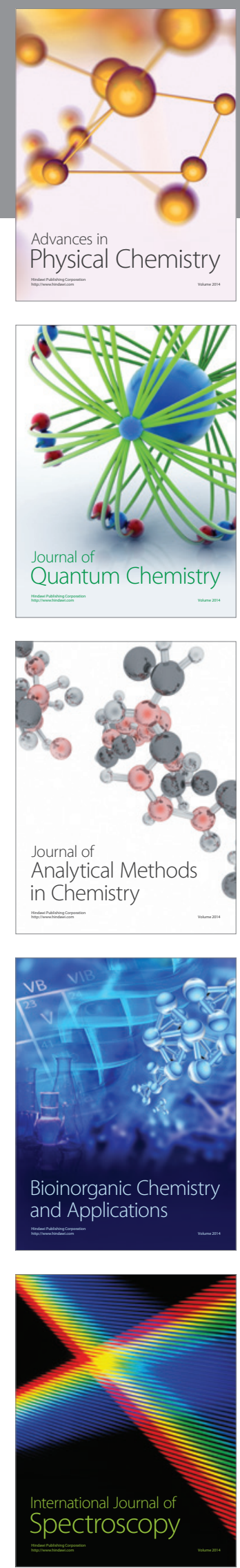